\title{
Platelet Serotonin in Newborns and Infants: Ontogeny, Heritability, and Effect of In Utero Exposure to Selective Serotonin Reuptake Inhibitors
}

\author{
GEORGE M. ANDERSON, KATHRYN CZARKOWSKI, NORMAN RAVSKI, AND \\ C. NEILL EPPERSON \\ Department of Laboratory Medicine [G.M.A.], Department of Psychiatry [K.C., C.N.E.], Department of \\ Obstetrics and Gynecology [N.R., C.N.E.], and the Child Study Center [G.M.A.], Yale University School \\ of Medicine, New Haven, Connecticut, 06520, U.S.A.
}

\begin{abstract}
Ontogeny of platelet serotonin (5-hydroxytryptamine, 5-HT) during the first year of life was examined in newborns and infants. The effects of in utero exposure to selective serotonin reuptake inhibitors (SSRI, including fluoxetine, sertraline, and citalopram) were examined by comparing cord blood 5-HT levels in exposed and unexposed newborns. Heritability was assessed by correlation of the platelet 5-HT values observed for mother-infant pairs. No age effect was observed in 1-49 wk-old infants $(r=0.13, p=0.49)$ and mean platelet 5-HT levels in infants $\left(241 \pm 102 \mathrm{ng} / \mathrm{mL}, n=33 ; 615 \pm 320 \mathrm{ng} / 10^{9}\right.$ platelets, $n=32$ ) were similar to those reported for older children and adults. However, significantly lower blood 5-HT levels were observed in newborns $(81.3 \pm 32.5 \mathrm{ng} / \mathrm{mL}, n=16, p<0.0001$; $297 \pm 101 \mathrm{ng} / 10^{9}$ platelets, $\left.n=11, p=0.0007\right)$ compared with the 1-49 wk-old infants. The mean cord blood 5-HT concentrations in newborns exposed in utero to SSRI $(n=8)$ were substantially lower than that seen in unexposed $(n=16)$ new-
\end{abstract}

ABSTRACT

borns $(20.6 \pm 14.4$ versus. $81.3 \pm 32.5 \mathrm{ng} / \mathrm{mL}, p=0.0001$; $90.7 \pm 55.4$ versus. $297 \pm 101 \mathrm{ng} / 10^{9}$ platelets, $\left.p=0.0005\right)$. Platelet serotonin levels (ng/ $10^{9}$ platelets) in mother-child pairs $(n=32)$ were significantly correlated $(r=0.415, p=0.018)$. The results indicate that, although platelet 5-HT is low at birth, values quickly increase and stabilize at near-adult levels by 1 mo of age. Gestational exposure to SSRI appears to substantially reduce platelet 5-HT uptake in the fetus, strongly suggesting that such exposure has important physiologic effects. The observed mother-infant correlation agrees with a previous report of high heritability in a large adult population. (Pediatr Res 56: 418422, 2004)

5-HT, 5-hydroxytryptamine

\section{Abbreviations}

QTL, quantitative trait loci

SSRI, selective serotonin reuptake inhibitor
There is a continuing interest in platelet serotonin (5-HT) due to its hemostatic, thrombogenic, and cardiovascular effects $(1,2)$, its utility in assessing the bioeffects of SSRI (3-5), and its alteration in several neuropsychiatric disorders (6-8). In prior work (9-11), we carried out a series of studies examining the effects of SSRI exposure on platelet 5-HT in nursing infants and in the present study seek to extend the available data regarding the normal ontogeny of platelet 5-HT in infants. We also wished to establish more firmly prior reports of low platelet 5-HT levels in newborn cord blood and to examine the effects of gestational SSRI exposure on cord blood levels.

Received October 30, 2003; accepted March 30, 2003.

Correspondence: George M. Anderson, Ph.D., Research Scientist, Child Study Center, Yale University School of Medicine, 230 S. Frontage Rd., New Haven, CT 06520, U.S.A.; e-mail: george.anderson@yale.edu

Portions of the research were supported by grants from the National Institute of Mental Health [\#01830-K23 (C.N.E.), \#MH-30929 (G.M.A.)] and the Pfizer and Eli Lily companies (C.N.E.).

DOI: 10.1203/01.PDR.0000136278.23672.A0
Finally, our investigations of nursing mother-infant pairs provided the opportunity to contribute to the limited data assessing the heritability of platelet 5-HT.

The platelet and neuronal 5-HT transporters are encoded by the same gene and appear identical in terms of pharmacology $(12,13)$. All platelet 5 -HT is accumulated by uptake through the platelet membrane 5-HT transporter and a number of studies have used the decline in platelet 5-HT seen after administration of reuptake inhibitors as an index of central and peripheral transporter blockade (3-5). The impact of central serotonin 5-HT modulation by SSRI during critical periods of brain development is unknown. Although preclinical studies indicate that 5-HT plays important roles in neurogenesis and neural growth (14-20), it is unclear how transporter inhibition affects early neurodevelopment in humans.

Research on fetal and neonatal exposure to SSRI has been recently reviewed $(10,11,21,22)$. Although substantial and physiologically meaningful infant SSRI exposure through breast-feeding by mothers receiving SSRI is probably infre- 
quent $(9-11,23)$, gestational exposure has been reported to have marked biochemical effects and may have significant clinical effects $(21,22)$. Elucidation of the normal ontogeny of platelet 5-HT is beneficial when attempting to assess the degree of uptake inhibition in fetuses and infants of mothers receiving SSRI. Measurements in neonates may also help in understanding the role of serotonin in pregnancy and placental physiology.

Estimation of the familiality and heritability of platelet 5-HT is of interest when attempting to understand the underlying bases of group mean alterations seen in children with autism spectrum disorders $(6,7)$. Recent evidence suggests that adult platelet 5-HT levels are extremely heritable $(24,25)$. However, available heritability data in children are meager and there were no data regarding the inheritance of the measure in infants.

\section{METHODS}

Subects. Thirty-three breast-feeding mother-infant pairs were referred by their primary care provider to the Yale Behavioral Gynecology Program for evaluation and consultation regarding the treatment of postpartum depression and/or the use of antidepressants during lactation. Nursing mothers (mean age, $33.3 \mathrm{y}$; range, 23-41 y) and infants (14 males, 19 females; mean age, $18.6 \mathrm{wk}, \mathrm{SD}=12.8$ ) had blood drawn by venipuncture and heelstick, respectively, for determination of whole blood 5-HT levels prior to the mother's initiation of fluoxetine $(n=12)$ or sertraline $(n=21)$ treatment. Blood was obtained between 1000 and $1400 \mathrm{~h}$ and collected into tubes containing dipotassium EDTA. The effects of exposure to SSRI during breast-feeding have been reported for 30 of the infants $(10,11)$.

Cord blood samples were obtained from eight infants (four males, four females) whose mothers were referred to the Yale Behavioral Gynecology Program due to their use of SSRI during pregnancy. Mothers (mean age, $33.1 \mathrm{y}$; range, 25-41 y) of exposed infants were receiving SSRI for treatment of depression or, in one case, obsessive-compulsive disorder at the time of delivery. Five were receiving fluoxetine $(10-40 \mathrm{mg} / \mathrm{d})$, two were being treated with sertraline $(50$ and $75 \mathrm{mg} / \mathrm{d}$, respectively), and one was receiving citalopram $(20 \mathrm{mg} / \mathrm{d})$. A blood sample was obtained from six of the mothers of the gestationally exposed infants. Cord blood samples were also obtained from 16 unexposed infants whose mothers gave birth at either of two local university-affiliated hospitals. Mothers of the exposed and unexposed infants were determined by their obstetrician to have had normal pregnancies and to have not used agents that might have affected platelet 5-HT levels (other than SSRI in the "exposed" group) or any psychotropic medications or substances of abuse (other than alcohol and tobacco) during pregnancy. Mothers of the exposed and unexposed groups were of similar age, socioeconomic status, and racial composition. The studies were approved by the Human Investigation Committee of Yale University School of Medicine and all mothers gave written informed consent.

Bioanalytical measurements. All specimens obtained for whole blood 5-HT analysis were initially kept at room tem- perature, 25 or $250 \mu \mathrm{L}$ portions were removed and stored at $-70^{\circ} \mathrm{C}$; portions were also sent for automated platelet count (Hematology Laboratory, Yale-New Haven Hospital, New Haven, CT, U.S.A.). Whole-blood 5-HT levels were determined in duplicate or triplicate by HPLC with fluorometric detection as previously described $(10,26)$. Nearly all of blood 5 -HT is located within the platelet and whole-blood 5-HT concentrations $(\mathrm{ng} / \mathrm{mL})$ can also be expressed on a per-platelet $\left(\mathrm{ng} / 10^{9}\right.$ platelets) basis if a whole-blood platelet count (platelets $/ \mathrm{mL}$ ) is obtained. Even in a situation where plasma levels of free 5-HT increased 10-fold, approximately $99 \%$ of whole blood 5-HT would be found in the platelet. Plasma levels of fluoxetine, norfluoxetine, sertraline and desmethylsertraline were determined by HPLC by Princeton Biomedical Laboratories (Princeton, NJ, U.S.A.).

Statistical analyses. Group data are given as mean \pm SD. $t$ and Mann-Whitney $U$ tests were used to test group differences depending on group size and distribution. Correlations were performed using either Pearson's $r$ or Spearman's rank correlation. Most analyses were performed using both $\mathrm{ng} / \mathrm{mL}$ and $\mathrm{ng} / 10^{9}$ platelets units for 5 -HT concentration to facilitate comparison with previous studies; as will be discussed, the units of $\mathrm{ng} / 10^{9}$ platelets are usually preferred.

\section{RESULTS}

Ontogeny of platelet 5-HT. The mean platelet 5-HT levels in the 1-49 wk-old nursing infants were $241 \pm 102 \mathrm{ng} / \mathrm{mL}$ $(n=33)$ and $615 \pm 320 \mathrm{ng} / 10^{9}$ platelets $(n=32)$ (Fig. 1). Infant blood samples were obtained before initiation of SSRItreatment of the mothers. As shown in Figure 2, no correlation was observed between infant platelet 5 -HT (ng/109 platelets) and age over the 1-49 wk-old age range ( $n=32$, Pearsons's $r=0.13, p=0.49)$. No significant correlations were observed between age and 5-HT expressed as $\mathrm{ng} / \mathrm{mL}(r=-0.06, p=$

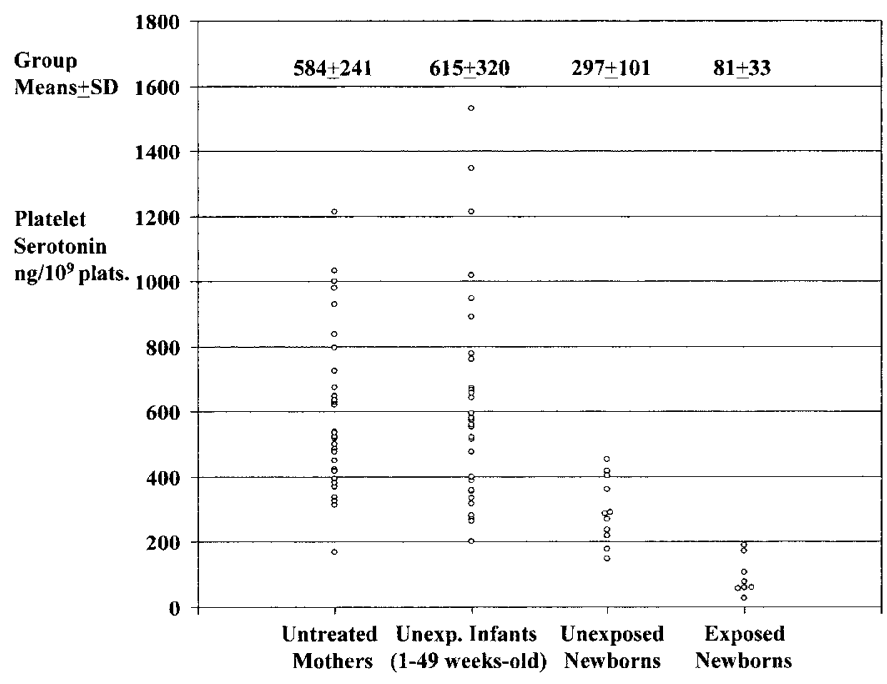

Figure 1. Individual platelet 5 -HT concentrations (ng/ $10^{9}$ platelets) observed for mothers of nursing infants $n=32$ ), nursing infants $(n=32)$, unexposed newborns $(n=11)$, and newborns exposed in utero to SSRI $(n=8)$; newborn analyses were performed using cord blood samples. Group means $( \pm \mathrm{SD})$ are given above the plotted data points. 


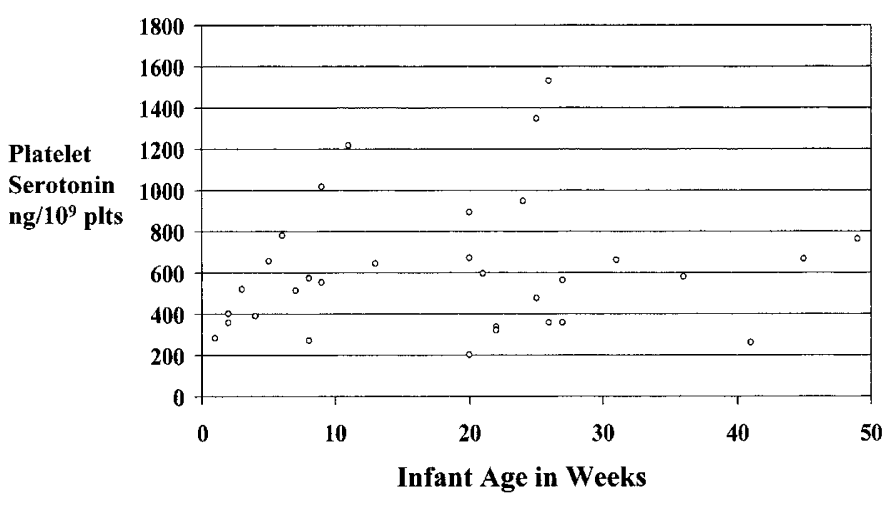

Figure 2. Infant platelet $5-\mathrm{HT}$ (ng/ $10^{9}$ platelets) concentrations plotted $v s$ infant age in weeks $(n=32)$. No correlation was observed between 5-HT level and age $(r=0.13, p=0.49)$.

$0.75)$ or between age and infant platelet count $(r=-0.26, p=$ $0.13)$.

The mean 5-HT levels observed in cord blood specimens obtained from unexposed newborns were $81.3 \pm 32.5 \mathrm{ng} / \mathrm{mL}$ $(n=16)$ and $297 \pm 101 \mathrm{ng} / 10^{9}$ platelets $(n=11)$. The newborn concentrations were significantly lower $(33 \%$ and $48 \%$ of the mean values seen in infants) than the values seen in the 1-49 wk-old infants (Mann-Whitney $U$ test, $z=5.3, p<$ 0.0001 and $z=3.4, p=0.0007$, respectively; see Fig. 1). The levels in newborns $(n=11)$ also tended to be lower than the levels observed in the group $(n=5)$ of $1-4$ wk-old infants $\left(297 \pm 101\right.$ versus $390 \pm 87 \mathrm{ng} / 10^{9}$ platelets), but the difference was not statistically significant $(z=1.4, p=0.16)$; the group comparison using $\mathrm{ng} / \mathrm{mL}$ units was also not significantly different.

Mean platelet 5-HT levels in the nursing mothers (all unmedicated) were $156 \pm 65.3 \mathrm{ng} / \mathrm{mL}$ or $584 \pm 241 \mathrm{ng} / 10^{9}$ platelets, depending on the units of expression of concentration ( $n=33$ and 32, respectively; see Fig. 1). Levels of platelet 5 -HT expressed as $\mathrm{ng} / 10^{9}$ platelets were not significantly different $(t=0.44, p=0.66)$ between mothers and infants. However, maternal concentrations expressed in units of $\mathrm{ng} / \mathrm{mL}$ were significantly lower than the levels seen in the 1-49 wk-old infants $(t=5.48, p<0.0001)$. The divergence seen for group mean $\mathrm{ng} / \mathrm{mL}$ values was due to the significantly higher platelet counts observed in the infants $(n=32)$ compared with their mothers $(432 \pm 137 / \mathrm{nL}$ versus $273 \pm 61.2 / \mathrm{nL}, t=8.0$, $p<0.0001$ ). It should be noted that 5 -HT levels expressed as $\mathrm{ng} / \mathrm{mL}$ tended to be correlated with platelet count in mothers $(r=0.31, p=0.085)$, but not in the infants $(r=0.03, p=$ $0.86)$.

Effects of in utero SRRI exposure on platelet 5-HT. As seen in Figure 1, platelet 5-HT concentrations in cord blood specimens obtained from eight newborns exposed in utero to an SSRI were significantly lower than those observed in unexposed newborns $(20.6 \pm 14.4$ versus $81.3 \pm 32.5 \mathrm{ng} / \mathrm{mL}$, $z=3.80, p=0.0001 ; 90.7 \pm 55.4$ versus $297 \pm 101 \mathrm{ng} / 10^{9}$ platelets, $z=3.47, p=0.0005$ ). Mean platelet 5-HT levels in the mothers of exposed newborns with available samples $(n=$ 6) were $43.2 \pm 39.7 \mathrm{ng} / \mathrm{mL}$ and $233 \pm 220 \mathrm{ng} / 10^{9}$ platelets. The two mothers with the highest 5-HT values (109 and 75.8 $\mathrm{ng} / \mathrm{mL}$, other values: $16.7,26.0,14.1$, and $17.8 \mathrm{ng} / \mathrm{mL}$ ) had the two infants with the highest 5-HT values (34.4 and 49.4 $\mathrm{ng} / \mathrm{mL}$, other values: $5.0,13.2,17.0,19.8,13.0$, and 13.0 $\mathrm{ng} / \mathrm{mL}$; see Fig. 1). Plasma drug and/or drug metabolite levels were available for four of the exposed infants and their mothers (two sertraline- and two fluoxetine-treated pairs). In three of the pairs, mothers' plasma drug levels were in the low end of the therapeutic range (sertraline, 26 and $24 \mathrm{ng} / \mathrm{mL}$; fluoxetine + norfluoxetine, $78 \mathrm{ng} / \mathrm{mL}$ ), with infant levels ranging from 25 to $85 \%$ of the mother's values. The one infant-mother pair with the highest plasma levels of fluoxetine + norfluoxetine (mother, $310 \mathrm{ng} / \mathrm{mL}$; infant, $437 \mathrm{ng} / \mathrm{mL}$ ), had the infant with the lowest observed platelet serotonin value $(5.0 \mathrm{ng} / \mathrm{mL})$.

Heritability of platelet 5-HT. An estimation of additive heritability $\left(\mathrm{h}^{2}\right)$ was obtained by correlation of maternal and infant 5-HT (ng $10^{9}$ platelets) blood levels. A Pearson correlation of $r=0.415(n=32, p=0.018)$ was observed, giving a heritability $\left(\mathrm{h}^{2}=2 r\right)$ estimate of 0.83 . When $\mathrm{ng} / \mathrm{mL}$ was used as the unit of 5-HT concentration, the observed correlation was $r=0.511(n=33, p=0.0007)$. A high maternal-infant correlation was also observed for platelet count $(n=32, r=$ $0.566, p=0.018$ ). As discussed below, the $\mathrm{ng} / 10^{9}$ platelets unit may be preferable as it accounts for familial similarities in platelet count.

\section{DISCUSSION}

The measurements of platelet 5-HT in 1-49 wk-old infants indicated that there is little developmental change in levels after the first few weeks of life. The mean levels observed in the infants are similar to those reported for children and are only slightly higher than those seen in their mothers and typically reported for adults. Given the substantially lower mean values observed in cord blood (33\% and $48 \%$ of levels seen in older infants, depending upon the units), it appears that levels in newborns rapidly increase to the levels seen in older infants, children, and adults. Only a small number of 1- to 4-wk-old neonates were studied, so it is difficult to say exactly how quickly this early increase occurs. It is not clear whether the early increase in 5-HT is due to a change in the platelet's handling of 5-HT or to an increased exposure to 5-HT. There are some very limited data that suggest 5-HT platelet uptake is fully functional in newborns (27) and that the gut's production of 5-HT (as indexed by urinary 5-hydroxyindoleacetic acid) is lower in the first week of life (28). These reports suggest that the early rise may be due to increased exposure, and this would be consistent with the expected increase in gut 5-HT release as feeding begins (29-31). However, longitudinal studies examining levels of platelet, plasma, and urine 5-HT, as well as plasma and urine levels of 5-HIAA, over the first month of life are needed to clarify the time course and mechanism of the early rise in platelet 5 -HT.

The platelet 5-HT ontogeny results are in good agreement with the limited prior reports of levels in newborns and infants, both in terms of the absolute levels observed and the apparent early low levels (32-36). Although most previous studies have reported 5-HT concentrations in units of $\mathrm{ng} / \mathrm{mL}$, the tendency for $\mathrm{ng} / \mathrm{mL}$ values to positively correlate with platelet count, observed here and elsewhere (37), suggests that the $\mathrm{ng} / 10^{9}$ 
platelets unit of concentration is preferred and a greater effort should be made to use this form of expression. The positive correlation presumably results from the greater available platelet pool able to serve as a site of 5-HT sequestration in subjects with higher platelet counts.

Gestational exposure to SSRI appeared to lead to significantly lower platelet 5-HT levels, with mean levels in exposed infants $25 \%(\mathrm{ng} / \mathrm{mL})$ and $34 \%\left(\mathrm{ng} / 10^{9}\right.$ platelets) of levels in unexposed infants. The mean $5-\mathrm{HT} \mathrm{ng} / \mathrm{mL}$ levels observed in SSRI-exposed and unexposed infants were in excellent agreement with the means recently reported for exposed and unexposed newborns $(21.5$ and $68.1 \mathrm{ng} / \mathrm{mL}$, respectively; only $\mathrm{ng} / \mathrm{mL}$ units reported) by a Finnish group (21). The percentage lowering seen in 5-HT $(\mathrm{ng} / \mathrm{mL})$ in the exposed Finnish infants (31\% of unexposed) differed only slightly from that observed here. The lower platelet 5-HT concentrations observed strongly suggest that SSRI-exposure results in significant inhibition of the 5-HT transporter. Based on animal studies, it is probable that a similar extent of inhibition occurs centrally and peripherally.

It is worth noting that platelet 5-HT levels are typically reduced to $5-20 \%$ of baseline levels in patients receiving clinical doses of SSRI. Thus, it appears that gestationally exposed fetuses have a bioeffect at or near that achieved in their mothers and in other SSRI-medicated patients. This similarity in bioeffect is consistent with the plasma drug levels that have been reported to occur in gestationally exposed newborns (see ref. 21 for review) and with the plasma drug levels we observed in a subset of subjects. Although the acute behavioral and long-term neurodevelopmental effects of gestational exposure are unclear, it is becoming clear that the primary pharmacological effect of the SSRIs - uptake inhibition - is usually manifest in utero in fetuses of mothers receiving fluoxetine or sertraline. It appears that brain extracellular levels of 5-HT increase 2- to 3-fold after SSRI administration in primate (38), presumably by reducing clearance. However, it is not clear what magnitude of increase occurs in the plasma or peripheral tissues.

The maternal-infant Pearson correlation of $r=0.415$ observed for 5 -HT (ng/10 $10^{9}$ platelets) was slightly lower than the theoretical maximum of $r=0.50$ expected for a parent-child correlation of a completely additively genetically determined trait. The estimated narrow heritability $\left(\mathrm{h}^{2}=2 r\right)$ of 0.84 could have been inflated due to familiality arising from shared environment; breast-feeding may increase the likelihood of this possibility. Although all subjects were Caucasian, assortative mating may also have inflated the heritability estimate. An even higher heritability $\left(\mathrm{h}^{2}=1.02\right)$ was estimated for 5 -HT when using $\mathrm{ng} / \mathrm{mL}$ units of concentration. The strong correlation $(r=0.566)$ observed between maternal and infant platelet counts coupled with the tendency for $5-\mathrm{HT} \mathrm{ng} / \mathrm{mL}$ concentration to correlate with platelet count may have further inflated the heritability estimate for platelet 5-HT expressed as $\mathrm{ng} / \mathrm{mL}$. The substantial mother-infant correlation seen for platelet 5-HT agrees with a previous report of high heritability in a large adult population $(24,25)$, and indicates that human platelet 5-HT is highly genetically determined in both infants and adults. However, as mentioned, the use of $\mathrm{ng} / \mathrm{mL}$ units in the prior study may have led to a confounding of platelet 5-HT and platelet count heritabilities. Although platelet 5-HT appears to be highly heritable, the genetic mechanisms of the inheritance are only beginning to be explored $(24,25,39)$. Identification of major quantitative trait loci (QTL) for platelet 5-HT should facilitate research examining the bases of group differences reported in certain neuropsychiatric disorders.

Several limitations of the present study ought to be noted. The group of newborns exposed in utero to SSRI was small ( $n$ $=8$ ), limiting conclusions about the magnitude of the reduction occurring during gestational exposure and about possible differences between drugs. The group effect seen was, however, quite similar to that recently observed in a Finnish study (21). Comparisons between the exposed and unexposed groups of newborns also are limited, here and elsewhere (21), by the lack of comparison groups matched for maternal disorder. Thus, some of the group difference seen might have arisen from genetic or environmental differences associated with or resulting from the mothers' psychiatric disorder or symptomatology. The calculated mother-infant correlations and heritabilities could have been inflated due to shared environment factors. Reports of platelet 5-HT being a stable trait and the similarity of the mean infant levels to adult levels tend to support the idea that similar parent-offspring correlations would be seen in older children.

In summary, although platelet 5-HT is low at birth, values appear to quickly increase and stabilize at near-adult levels within weeks of birth. Further study of this early rise may enhance understanding of early intestinal functioning and would, at the very least, provide better ontogenetic norms. Gestational exposure to SSRI appears to substantially reduce platelet 5-HT uptake in infants, strongly suggesting that such exposure has important physiologic effects. Recent reports have indicated that gestational exposure to SSRI can adversely affect neonate behavior and well being $(21,22,40)$. In addition, adverse effects of the SSRI in adult patients can include nausea, diarrhea, and bruising. These reports and observations underscore the potential clinical importance of using platelet 5-HT to estimate the drugs' bioeffect in individual newborns and neonates. The high parent-offspring heritability observed here and elsewhere is encouraging in terms of identifying underlying genetic and biologic determinants of platelet 5-HT. Clarification of these factors would facilitate research in the areas mentioned above and in neuropsychiatric disorders where alterations in platelet 5-HT have been identified.

Acknowledgments. The authors thank the women and infants who took part in this study. We also thank the obstetricians and midwives of the County Obstetrics and Gynecology practice for their critical efforts in recruiting the participation of SSRI-unexposed infants.

\section{REFERENCES}

1. De Clerck FF, Janssen PA 1990 Amplification mechanisms in platelet activation and arterial thrombosis. J Hypertens Suppl 8:S87-S93

2. MacLean MR 1999 Pulmonary hypertension, anorexigens and 5-HT: pharmacological synergism in action? Trends Pharmacol Sci 20:490-495

3. Buss LJ, Lund J, Bechgaard E, Sondergaard I 1970 Inhibition of 5-HT uptake into platelet in mice treated chronically with chorimipramine and femoxetine. Psychopharmacology (Berl) 64:149-153 
4. Fuller RW, Wong DT 1990 Serotonin uptake and serotonin uptake inhibition. Ann N Y Acad Sci 600:68-80

5. Karege F, Widmer J, Bovier P, Gaillard J 1994 Platelet serotonin and plasma tryptophan in depressed patients: effect of drug treatment and clinical outcome. Neuropsychopharmacology 10:207-214

6. Anderson GM 2002 Genetics of childhood disorders: XLV. Autism, part 4: serotonin in autism. J Am Acad Child Adolesc Psychiatry 41:1513-1516

7. Mulder E, Anderson GM, Kema I, de Bildt A, van Lang NDJ, den Boer JA, Minderaa RB 2004 Platelet serotonin in pervasive developmental disorders and mental retardation. J Am Acad Child Adolesc Psychiatry 43:491-499

8. Inestrosa NC, Alarcon R, Arriagada J, Donoso A, Alvarez J 1993 Platelets of Alzheimer patients: increased counts and subnormal uptake and accumulation of [14C]5-hydroxytryptamine. Neurosci Lett 163:8-10

9. Epperson CN, Anderson GM, McDougle CJ 1997 Sertraline and breastfeeding. N Engl J Med 336:1189-1190

10. Epperson CN, Czarkowski KA, Ward-O'Brien D, Weiss E, Gueorguieva R, Jatlow P, Anderson GM 2001 Maternal sertraline treatment and serotonin transport in breastfeeding mother-infant pairs. Am J Psychiatry 158:1631-1637

11. Epperson CN, Jatlow PI, Czarkowski K, Anderson GM 2003 Maternal fluoxetine treatment in the postpartum period: effects on platelet serotonin and plasma drug levels in breastfeeding mother-infant pairs. Pediatrics 112:e425-e429

12. Lesch KP, Wolozin BL, Murphy DL, Reiderer P 1993 Primary structure of the human platelet serotonin uptake site: identity with the brain serotonin transporter. J Neurochem 60:2319-2322

13. Rudnick G, Humphreys CJ 1992 Platelet serotonin transporter. Methods Enzymol 215:213-224

14. Buznikov GA, Lambert HW, Lauder JM 2001 Serotonin and serotonin-like substances as regulators of early embryogenesis and morphogenesis. Cell Tissue Res 305:177-186

15. Moiseiwitsch JR, Lauder JM 1995 Serotonin regulates mouse cranial neural crest migration. Proc Natl Acad Sci U S A 92:7182-7186

16. Lauder JM 1993 Neurotransmitters as growth regulatory signals: role of receptors and second messages. Trends Neurosci 16:233-240

17. Lesch KP 2001 Variation of serotonergic gene expression: neurodevelopment and the complexity of response to psychopharmacological drugs. Eur Neuropsychopharmacol $11: 457-474$

18. Whitaker-Azmitia PM, Druse M, Walker P, Lauder JM 1996 Serotonin as a developmental signal. Behav Brain Res 73:19-29

19. Bal-Klara A, Bird MM 1990 The effects of various antidepressant drugs on the fine-structure of neurons of the cingulate cortex in culture. Neuroscience 37:685-692

20. Vorhees CV, Acuff-Smith KD, Schilling MA, Fisher JE, Moram MS, Buelke-Sam J 1994 A developmental neurotoxicity evaluation of the effects of prenatal exposure to fluoxetine in rats. Fundam Appl Toxicol 23:194-205

21. Laine K, Heikkinen T, Ekblad U, Kero P 2003 Effects of exposure to selective serotonin reuptake inhibitors during pregnancy on serotonergic symptoms in newborns and cord blood monoamine and prolactin concentrations. Arch Gen Psychiatry $60: 720-726$
22. Oberlander TF, Eckstein Grunau R, Fitzgerald C, Ellwood AL, Misri S, Rurak D, Riggs KW 2002 Prolonged prenatal psychotropic medication exposure alters neonatal acute pain response. Pediatr Res 51:443-453

23. Suri R, Stowe ZN, Hendrick V, Hostetter A, Widawski M, Altshuler LL 2002 Estimates of nursing infant daily dose of fluoxetine through breast milk. Biol Psychiatry 52:446-451

24. Ober C, Abney M, McPeek MS 2001 The genetic dissection of complex traits in a founder population. Am J Hum Genet 69:1068-1079

25. Abney M, McPeek MS, Ober C 2001 Broad and narrow heritabilities of quantitative traits in a founder population. Am J Hum Genet 68:1302-1307

26. Anderson GM, Feibel FC, Cohen DJ 1987 Determination of serotonin in whole blood, platelet-rich plasma, platelet-poor plasma and plasma ultrafiltrate. Life Sci 40:1063-1070

27. Tsao CH, Green D Schultz K 1976 Function and ultrastructure of platelets of neonates: enhanced ristocetin aggregation of neonatal platelets. Br J Hematol 32:225-233

28. Mashige F, Matsushima Y, Kanazawa H, Sakuma I, Takai N, Bessho F, Ohkubo A 1996 Acidic catecholamine metabolites and 5-hydroxyindoleacetic acid in urine: the influence of diet. Ann Clin Biochem 33:43-49

29. Anderson GM, Stevenson JM, Cohen DJ 1987 Steady-state model for plasma free and platelet serotonin in man. Life Sci 41:1777-1785

30. Gershon MD 1998 The Second Brain. Harper-Collins, New York

31. Mulder EJ, Anderson GM, Kema IP, Minderaa RB 2002 Reactivity of serotonin in whole blood. Biol Psychiatry 51:266-268

32. Berman JL, Justice P, Hsia DY 1965 The metabolism of 5-hydroxytryptamine (serotonin) in the newborn. J Pediatr 67:603-608

33. Hazra M, Benson S, Sandler M 1965 Blood 5-hydroxytryptamine levels in the newborn. Arch Dis Child 40:513-515

34. Tu J, Wong CY 1976 Serotonin metabolism in normal and abnormal infants during the perinatal period. Biol Neonate 29:187-193

35. Flachaire E, Beney C, Berthier A, Salandre J, Quincy C, Renaud B 1990 Determination of reference values for serotonin concentration in platelets of healthy newborns, children, adults and elderly subjects by HPLC with electrochemical detection. Clin Chem 36:2117-2120

36. De Villard R, Flachaire E, Laujin A, Maillet J, Revol O, Charles S, Mamelle JC, Renaud B, Quincy C 1991 Platelet serotonin concentration in children under 5 years of age. Pediatrie 46:813-816

37. McBride PA, Anderson GM, Hertzig ME, Snow ME, Thompson SM, Khait VD, Shapiro T, Cohen DJ 1998 Effects of diagnosis, race, and puberty status on platelet serotonin levels in autism and mental retardation. J Am Acad Child Adolesc Psychiatry $37: 767-779$

38. Anderson GM, Bennett AJ, Weld KP, Pushkas JG, Ocame DM, Higley JD 2002 Serotonin in cisternal cerebrospinal fluid of the rhesus monkeys: basal levels and effects of sertraline administration. Psychopharmcology 161:95-99

39. Weiss L, Veenstra-VanderWeele J, Abney M, Dytch H, McPeek MS, Cheng S, Cook E, Pober C 2003 Genome-wide association mapping in a founder population identifies ITGB3 as a QTL for whole blood serotonin levels. Am J Hum Genet 73(suppl 5):178

40. Zeskind PS, Stephens LE 2004 Maternal selective serotonin reuptake inhibitor use during pregnancy and newborn behavior. Pediatrics 113:368-375 